\title{
A REDUÇÃO DOS CUSTOS NO USO DE ARRANJOS PRODUTIVOS LOCAIS NA GESTÃO COMPETITIVA DA LOGÍSTICA DE SUPRIMENTOS. ESTUDO DE CASO NO APL LEITE \& SOL DA CADEIA PRODUTIVA DO LEITE NO ESTADO DO CEARÁ
}

\section{THE COST REDUCTION ON THE USE OF LOCAL PRODUCTIVE ARRANGEMENT ON COMPETITIVE SUPPLY LOGISTIC. STUDY ABOUT THE CASE ON APL MILK AND SUN OF THE PRODUCTIVE CHAIN OF MILK IN CEARÁ STATE}

\author{
Célia Maria Braga Carneiro \\ Mestre em Controladoria e Professora da Universidade Federal do Ceará \\ Universidade Federal do Ceará \\ Departamento de Contabilidade \\ Endereço: Rua Gonçalves Ledo, 941 apto.XXXX, Fortaleza - Ceará \\ Telefone: (85) 3253.4802 \\ e-mail: celiabc@secrel.com.br
}

\section{Edmar José Zorzal}

Mestre em Engenharia de Produção (UFSC)

Professor da Faculdade Novo Milênio

Endereço:Av.Governador Bley, Ed.Bemge. $2^{\circ}$ andar. Centro Vitória - ES- CEP29.010-150

Telefone: (27) 3132.8280

e-mail: edmar.zorzal@cesan.com.br

\section{Greyciane Passos dos Santos}

Consultora e Mestranda em Logística e Pesquisa Operacional

Universidade Federal do Ceará (UFC) e Bolsista da Funcap

Pró-Reitoria de Pesquisa e Pós-Graduação UFC

Endereço: Avenida José Bastos. 3261, Fortaleza - Ceará

Telefone: (85) 3494.9119

e-mail: greycianep@yahoo.com.br

\section{Marta Maria de Mendonça Bastos}

Doutora em Economia de Transportes e Professora do Curso de Mestrado em Logística e

Pesquisa Operacional da Universidade Federal do Ceará

Universidade Federal do Ceará 


\author{
Centro de Tecnologia \\ Endereço: Rua Frei Mansueto - Papicu - Fortaleza - Ceará \\ Telefone: (85) 3366.9655 \\ e-mail:marta@det.ufc.br
}

\title{
Rosana Venâncio Nunes
}

Pesquisadora e Graduanda do Curso de Geografia da Universidade Estadual do Ceará Endereço: Edmundo Linhares,35 Fortaleza - Ceará - CEP 60.420-340

Telefone: (85) 3491.7707

e-mail: rosanavnunes@hotmail.com

\section{Rosângela Venâncio Nunes}

\author{
Pesquisadora e Mestranda em Logística e Pesquisa Operacional \\ Universidade Federal do Ceará (UFC) e Bolsista da Funcap \\ Pró-Reitoria de Pesquisa e Pós-Graduação UFC \\ Endereço: Edmundo Linhares,35 Fortaleza - Ceará - CEP 60.420-340 \\ Telefone: (85) 3491.7707 \\ e-mail: angelnuness@yahoo.com.br
}

\section{RESUMO}

As vantagens competitivas duradouras cada vez mais dependem da cooperação interempresas no atual cenário econômico globalizado. Essas relações são complexas e, a sua compreensão requer o estudo das suas principais formas de organização. O objetivo geral deste trabalho é analisar a redução de custos no uso de arranjos produtivos locais na gestão competitiva da logística de suprimento das empresas, utilizando o caso de um Arranjo Produtivo Local da cadeia produtiva do leite no Estado do Ceará, aqui denominado como Leite \& Sol. Buscou-se verificar se as empresas que compõem a cadeia analisada alcançaram uma significativa redução em custos desenvolvendo suas atividades dentro do arranjo produtivo. Metodologicamente, utilizou-se, prioritariamente, o método dedutivo, e, subsidiariamente, o indutivo. A pesquisa pode ser classificada do ponto de vista de sua natureza como pesquisa aplicada e descritiva, visando descrever e analisar as características das empresas pertencentes ao Arranjo Produtivo Local analisado.

Palavras-chave: Arranjos Produtivos. Custos. Logística de Suprimentos 


\begin{abstract}
The advantages of competitions that have most last every time more depends of cooperation enterprise at these moment global economic scenery. These relations are complex and, its comprehension requests the study of the main ways of organizations. The general goal this work is to analyze the cost reduction applications local productive arrangements on the management's competition logistic enterprise needs, to make use of the productive chain of milk in Ceará State. Here called like Milk and Sun. Searched to check if the enterprises that consist the sequence productive analyzed to reach a meaning cost reduction developing its activist inside the productive arrangement. Metodologicament done use, at principal, the deductive method, and, subsidiaryment the inductive method. The search can be classified the point of view about its nature like a search applied and described, looking for describe and to analyze the characteristics of the enterprises the belong Local Productive Arrangement analyzed.
\end{abstract}

Key-words: Local productive arrangement. Cost. Supply logistic.

\title{
1. INTRODUÇÃO
}

A redução dos custos representa um dos principais mecanismos para as empresas atingirem vantagem competitiva na visão de Michael Porter. Muitas entidades têm concentrado esforços na melhoria das atividades, enquanto outras investem no seu relacionamento na cadeia externa, com a finalidade de obter redução de custos ou diferenciação. Neste estudo, os arranjos produtivos têm ganhado importância na estrutura de logística de suprimento das empresas, objetivando redução de custos, alcançando e mantendo vantagem competitiva em um setor com pequenas margens de lucro.

Porter (1989, p.20) acredita que "a localização geográfica de uma atividade pode afetar seu custo de várias maneiras.” As localizações diferem nos custos da mão-de-obra, da administração, das matérias primas, energia e outros fatores. Quanto aos níveis salariais e aos impostos, estes variam de acordo com a cidade, país e região com incentivos. O custo da infra-estrutura de uma empresa pode ser afetado pelo padrão existente deste elemento de instalação da empresa no local, as condições climáticas, os aspectos culturais e também 
diferem na localização, pois afetam não só as necessidades de produtos, mas também a maneira que uma empresa executa suas atividades, devido à localização das suas matériasprimas e dos mercados consumidores, que definem custos logísticos internos e externos.

O uso dos arranjos produtivos pode contribuir não só para a criação de entidades mais competitivas, como também para a melhoria social e econômica através da geração de emprego e renda em áreas socialmente críticas, como o Estado do Ceará.

O problema científico proposto por esse estudo é buscar a resposta para seguinte indagação: qual o papel da redução dos custos no uso de arranjos produtivos locais na gestão competitiva da logística de suprimentos?

$\mathrm{Na}$ busca da resolução para o problema científico proposto, a pesquisa tem como objetivo geral analisar a redução de custos no uso de arranjos produtivos locais como estratégia de gestão competitiva na logística de suprimentos das empresas, utilizando-se do caso de um APL de cadeia produtiva do leite no Estado do Ceará, denominado, neste estudo, como APL Leite \& Sol.

E para alcançar o objetivo geral, tem-se como objetivos específicos fazer uma breve contextualização sobre a logística e os arranjos produtivos, abordando seus aspectos gerais e suas formas de cooperação inter-empresas e análise da cadeia produtiva como parte integrante de arranjos produtivos. Em seguida, avalia-se um APL da cadeia produtiva do leite no Estado do Ceará e a análise conjunta de dados coletados em 83 microempresas que compõem o APL da cadeia do leite, que foram agrupados em três grupos, demonstrando a redução de custos gerada pelo arranjo produtivo.

O método de pesquisa utilizado foi o dedutivo prioritariamente, e subsidiariamente o indutivo. A pesquisa pode ser classificada, do ponto de vista de sua natureza, como pesquisa aplicada.

Em função dos seus objetivos, a pesquisa é basicamente quantitativa, pois esta abordagem considera que tudo pode ser quantificável, traduzindo números em opiniões e informações para classificá-las e analisá-las. Ainda com relação à abordagem, para cumprir outros objetivos da pesquisa aplicam-se também procedimentos qualitativos complementares. Trata-se de pesquisa descritiva visando delinear as características das empresas pertencentes ao APL da cadeia de leite do Estado do Ceará. As técnicas de pesquisas foram: a 
documentação indireta bibliográfica, documental e a documentação direta com aplicação de estudo de caso e observação direta intensiva.

\section{Conceito de Logística e suas subdivisões}

No meio científico, há muitos conceitos de logística. No entanto, o conceito mais adequado aos objetivos desta pesquisa é citado por Bastos (2007, p.12) como "um conjunto de técnicas e estratégias interdependentes que, aplicadas a uma série de funções da atividade econômica, é capaz de otimizá-las dentro de um determinado contexto sócio-econômico, tecnológico e cultural". Esse conceito apresenta a logística como uma filosofia de administração, de forma a se adaptar às novas exigências de desempenho para as entidades, apresentando uma nova visão empresarial, uma nova ordem da atividade econômica que se encaixa perfeitamente aos conceitos de arranjos produtivos locais.

Quanto à classificação da logística, Bastos (2007, p.12) identifica duas subdivisões para a mesma: a macrologística e a micrologística. A macrologística trata da concepção estratégica espacial da atividade econômica e de suas infra-estruturas de apoio.

A micrologística ou logística das entidades, tem como manifestações tangíveis os procedimentos utilizados pela otimização de fluxos, diminuição de custos, aumento da qualidade dos produtos (bens e serviços), racionalização da produção e da distribuição, bem como redução dos níveis de estoque de uma empresa, tendo como objetivo possibilitar o aumento da produtividade, da rentabilidade dos investimentos e do nível de serviços oferecidos aos seus clientes.

Dessa forma, a micrologística representa uma nova visão empresarial e ordem da atividade econômica, está subdividida em: logística de suprimento (focada na organização e no abastecimento das unidades de produção); logística de produção (direcionada na coordenação da produção nas unidades de produção); logística de distribuição (focada na ordenação da distribuição de componentes e bens de consumo final); e logística de pós-venda (direcionada na organização do apoio a pós-venda). 
Nesse estudo utiliza-se a micrologística para analisar a redução de custos de suprimentos no patrimônio das empresas que compõem a cadeia de leite no Ceará estruturada em um arranjo produtivo local.

\section{Aglomerações produtivas de empresas com enfoque em arranjos produtivos}

A literatura que envolve o campo das pesquisas feitas na área de aglomerações produtivas apresenta uma variada tipologia de aglomerações de empresas, bem como seus conceitos e definições. Porém, ao estudar uma aglomeração é imprescindível considerar que sua caracterização irá variar de acordo com o estágio de desenvolvimento e, também, de acordo com o foco que será dado à aglomeração produtiva. Assim sendo, uma aglomeração produtiva de empresas pode surgir em função de economias externas Marshallianas puras (economias tecnológicas, de mercado e de organização) e independente de seu tamanho ou tempo de existência, não necessariamente deve ser classificada como um arranjo.

A simples coexistência destas empresas em um mesmo espaço geográfico não lhes confere o caráter de arranjo produtivo ou distrito industrial dentro da visão abordada neste trabalho, que pressupõe interação entre diversos agentes. Para Suzigan (2000), um APL embrionário pode ser caracterizado como aquele que possui pouca importância para o seu setor e convive, na região, com outras atividades econômicas. Representa a categoria mais numerosa de sistemas produtivos locais nos dias de hoje. A política industrial para estes embriões deveria estar associada a um conjunto de etapas, cada qual com diretrizes locais claras, tanto em termos de recursos quanto em termos de comprometimento. $\mathrm{O}$ funcionamento dos aglomerados econômicos é complexo, pois envolve aspectos econômicos, administrativos, financeiros, culturais, sociais e ambientais. Os diferentes tipos de aglomerados econômicos podem ser classificados como: distritos industriais, clusters e arranjos produtivos, que serão explicitados a seguir.

\section{a) Distritos Industriais}

A origem dos conceitos sobre distritos industriais remonta ao início do século XX. Marshall em Principles of Economy (1920) foi o precursor do conceito. Segundo o autor esta 
modalidade de aglomerado de empresas geraria uma série de externalidades, tais como: mãode-obra especializada, acesso a fornecedores e serviços especializados e disseminação do conhecimento entre as empresas.

Para Pagani (2006, p.49), "no Brasil os distritos industriais referem-se, particularmente, a uma área especialmente designada para o desenvolvimento de atividades industriais diversas, não havendo, entre as empresas deles participantes, qualquer vínculo, seja por afinidade de segmento ou por complementaridade de processos ou produtos. No entanto, isto não significa que não possa haver mais de uma empresa atuante no mesmo segmento, instaladas no mesmo distrito, o que no caso caracterizar-se-ia por mera coincidência dentro do foco aqui colocado".

Este fato, até então, não é pré-requisito para a criação e continuidade de existência de um distrito industrial. Os terrenos que fazem parte desta área são geralmente doados pelo Estado, e visam apoiar as atividades industriais buscando gerar emprego e renda na economia local. Outros benefícios podem ser concedidos, como isenção por tempo determinado de tributos fiscais de âmbito municipal e até mesmo estadual, dependendo da negociação junto ao governo, com uso de incentivos fiscais.

\section{b) Clusters}

Segundo a REDESIST (2005), ao longo da década de oitenta desenvolveu-se o conceito de cluster centrado na análise das formas de relações interempresariais, vinculadas à existência de alguns aglomerados industriais regionais de sucesso em termos mundiais. Este termo é comumente utilizado para denominar as aglomerações de empresas. O termo associase à tradição anglo-americana e refere-se a aglomerados de empresas que desenvolvem atividades similares.

Segundo Amaral Filho (2000, p.13), “a estratégia baseada no cluster, de origem predominantemente anglo-saxônica, pretende funcionar como uma espécie de síntese dos conceitos, ou estratégias citadas, como os distritos industriais, na medida em que pretende ser mais abrangente, não só por incorporar aspectos do conceito precedente, mas porque não fica restrito às pequenas e médias empresas".

Segundo Amorim (1998, p.3), cluster denomina um conjunto numeroso de empresas, em geral pequenas e médias, operando em regime de intensa cooperação, onde cada uma das 
firmas executa um estágio de processo de produção. Essas empresas participam de um mesmo negócio, como produção de calçados ou confecções, embora cada uma das firmas seja uma entidade autônoma. Esse tipo de arranjo fortalece os elos da cadeia de valor.

Para Suzigan (2000, p.7), “as características mais importantes de um cluster resumem-se em: interação das empresas por meio de interconexões de produção, comércio e distribuição, cooperação em marketing, promoção de exportações, compra de insumo e atividades de P \& D.” É necessário, também, verificar a presença de economias externas, concentração de mão-de-obra especializada, transbordamentos (spillovers) tecnológicos, entre outros, fatores que favorecem a especialização de uma atividade econômica e de desenvolvimento econômico regional.

\section{c) Arranjos Produtivos Locais (APLS)}

De acordo com a REDESIST (2005) os exemplos ocorridos nos distritos industriais Italianos da chamada Terceira Itália e no Vale do Silício, Califórnia (USA), deram origem ao termo Arranjo Produtivo Local (APL). Os Arranjos Produtivos Locais são aqueles casos onde as empresas participantes ainda não estão tão fortemente vinculadas e articuladas.

Para o BNDES (2005), a característica principal dos APLS é a presença de pequenas e médias empresas concentradas espacialmente em alguns dos elos de uma cadeia produtiva e o alto índice de cooperação entre as empresas.

Os arranjos produtivos são aglomerações de empresas localizadas em um mesmo território, que apresentam especialização produtiva e mantêm algum vínculo de articulação, interação, cooperação e aprendizagem entre si e com atores locais como governo, associações empresariais, instituições de crédito, ensino e pesquisa. A concentração geográfica não é suficiente para explicar o arranjo produtivo local, mas é um dos pontos de partida para entendê-lo. A discussão sobre arranjos produtivos inicia-se com as denominações que são dadas às aglomerações de empresas, entre as mais comuns destacam-se cluster e distritos industriais. No entanto, há especificidades estruturais que devem ser consideradas nos conceitos de distritos industriais, de clusters e de arranjos produtivos para uma melhor compreensão dessas aglomerações produtivas, assim como suas estratégias de competitividade e desenvolvimento local. 
4.1. Aspectos Comuns e diferenças existentes entre Arranjos Produtivos Locais, Distritos Industriais e Clusters

Distrito Industrial, Cluster e Arranjo Produtivo são utilizados para definir aglomerações de empresas com vínculos entre si localizadas em um determinado "território" e que desenvolvem atividades em torno de um produto principal, atividade esta desenvolvida de acordo com a potencialidade do território. O Quadro 1 descreve os aspectos comuns entre essas abordagens.

Quadro 1:Aspectos comuns das abordagens de aglomerados locais

\begin{tabular}{|l|l|}
\hline Aspectos & Elementos comuns entre Distritos Industriais, Clusters e APL \\
\hline Localização & Proximidade ou concentração geográfica; \\
\hline Atores & Grupos de Pequenas Empresas; \\
& Pequenas empresas nucleadas por grande empresa; \\
& Associações, instituições de suporte, serviços, ensino e pesquisa, fomento, financeiras etc. \\
\hline Características & Intensa divisão do trabalho entre as empresas; \\
& Flexibilidade de produção e de organização; \\
& Especialização; \\
& Competição entre as empresas baseadas na inovação; \\
& Estreita colaboração entre as firmas e demais agentes; \\
& Relação de confiança entre os agentes; \\
& Complementaridades e sinergia. \\
\hline
\end{tabular}

Fonte: Lemos (2003) apud Duarte (2004, p.20)

No entanto, apesar das similaridades existentes entre os conceitos, existem algumas particularidades em cada um que devem ser consideradas, para definir a sua aplicabilidade local, de acordo com a estratégia de desenvolvimento, como evidencia o Quadro 2.

Quadro 2: Peculiaridade de cada Tipologia de Aglomeração

\begin{tabular}{|l|l|l|l|}
\hline \multicolumn{1}{|c|}{ Tipologia } & Distritos Industriais & Clusters & Arranjos Produtivos Locais \\
\hline $\begin{array}{l}\text { Parâmetro } \\
\text { Empresas }\end{array}$ & $\begin{array}{l}\text { Formada por } \\
\text { aglomerações de micro e } \\
\text { pequenas empresas. }\end{array}$ & $\begin{array}{l}\text { Formada por micro pequenas } \\
\text { empresas, mas pode também se } \\
\text { originar de uma grande } \\
\text { empresa. }\end{array}$ & $\begin{array}{l}\text { Constituídos por micro e } \\
\text { pequenas empresas, } \\
\text { apresentando baixo nível } \\
\text { tecnológico. }\end{array}$ \\
\hline $\begin{array}{l}\text { Intensidade } \\
\text { das relações }\end{array}$ & $\begin{array}{l}\text { Nenhuma liderança } \\
\text { sistemática. }\end{array}$ & $\begin{array}{l}\text { É uma concentração, } \\
\text { aglomeração ou agrupamento } \\
\text { setorial; Liderança da grande } \\
\text { empresa ou não sistemática. }\end{array}$ & $\begin{array}{l}\text { Envolvem a participação e a } \\
\text { interação de empresas } \\
\text { produtoras e fornecedoras de } \\
\text { insumos e equipamentos. }\end{array}$ \\
\hline
\end{tabular}


$\underline{\text { www.producaoonline.ufsc.br }}$

ISSN 1676 - 1901 / Edição especial/dezembro de 2007

Artigo selecionado dos anais - XIV Congresso Brasileiro de Custos

\begin{tabular}{|l|l|l|l|}
\hline $\begin{array}{l}\text { Forma de } \\
\text { concentração }\end{array}$ & $\begin{array}{l}\text { Liderança por } \\
\text { organizações de P\&D } \\
\text { baseado em confiança. }\end{array}$ & $\begin{array}{l}\text { Proximidade geográfica e } \\
\text { atuação no mesmo setor. }\end{array}$ & $\begin{array}{l}\text { Estruturas pouco } \\
\text { desenvolvidas, surgidas do } \\
\text { improviso dos produtores ou } \\
\text { das demandas da região. }\end{array}$ \\
\hline $\begin{array}{l}\text { Nível de } \\
\text { Cooperação }\end{array}$ & $\begin{array}{l}\text { Fortes relações entre as } \\
\text { empresas nas esferas } \\
\text { sociais, políticas e } \\
\text { econômicas. }\end{array}$ & Pouco discutida. & $\begin{array}{l}\text { É tida como uma fonte para } \\
\text { se obter vantagens } \\
\text { competitivas }\end{array}$ \\
\hline $\begin{array}{l}\text { Nível de } \\
\text { Competição }\end{array}$ & $\begin{array}{l}\text { Existe competição e } \\
\text { colaboração. }\end{array}$ & $\begin{array}{l}\text { É incentivado para conseguir } \\
\text { aumentar produção e melhorar } \\
\text { qualidade por meio da } \\
\text { inovação. }\end{array}$ & $\begin{array}{l}\text { É incentivado para aumentar } \\
\text { produção e dinamismo entre } \\
\text { as empresas. }\end{array}$ \\
\hline
\end{tabular}

Fonte: Elaborado pelos autores, com base nos conceitos apresentados.

Diante dos aspectos comuns e diferentes entre as aglomerações, cabe ressaltar que a existência de um mercado e relações mais transparentes que podem incitar tanto a competição quanto à cooperação, resultando em crescimento para as empresas, mantendo coletivamente um resultado favorável, contribuindo para o crescimento e o desenvolvimento local.

\subsection{APL e desenvolvimento local sustentável}

O desenvolvimento local é entendido como um processo que mobiliza pessoas e instituições buscando a transformação da economia e da sociedade locais, criando oportunidades de trabalho e de renda, superando dificuldades para favorecer a melhoria das condições de vida da população local.

O desenvolvimento do APL requer o crescimento dos níveis de confiança, cooperação, ajuda mútua e organização social, o que tem sido denominado de capital social.

Os arranjos produtivos locais surgem embrionariamente da "vontade" de um grupo de micro e pequenos empresários localizados num determinado território de vencerem as adversidades existentes, que são impedimentos para a sua manutenção e crescimento.

A sustentabilidade e a solidez de um APL dependem, entre outros fatores, dos níveis de entrosamento, coesão e de cooperação que se desenvolvem entre os seus componentes. As relações de cooperação devem ser continuamente cultivadas por todos e estimuladas, principalmente, pelas instituições que dão sustentação aos APLS, tais como: associações de produtores, órgãos públicos de assistência gerencial, prefeituras e órgãos de desenvolvimento. 
Segundo Kranz apud Silveira e Reis (2001, p.132), características como: flexibilidade, interdependência, parceria, diversidade e a reciclagem nos fluxos de matéria e energia são exigidas para se alcançar a sustentabilidade competitiva, que requer esforços contínuos e que afeta todas as decisões a serem tomadas na política local.

O desenvolvimento para alcançar a sustentabilidade busca condições objetivas de equilíbrio econômico e social, do político com as instituições, da produção com o meio ambiente, das necessidades de uma geração e a sobrevivência da humanidade, do consumo presente com o futuro e da responsabilidade social e a governança local com a sustentabilidade social.

Logo, o APL deve ser gerenciado para um objetivo que agregue valor à cadeia e proporcione a garantia de vantagem competitiva sustentável, por meio de uma gestão permanente do negócio, da cadeia e do território.

4.3. Vantagem Competitiva dentro do contexto de custeio da cadeia de suprimentos com enfoque em Direct Product Profitability (DPP)

A vantagem competitiva surge, basicamente, segundo Porter (1989, p.30), do valor que uma empresa consegue criar para seus compradores e que ultrapassa o custo de fabricação. Fica evidente que existe uma forte e direta relação entre vantagem competitiva e agregação de valor, pois devido ao aumento de valor implementado pelo fabricante no produto ou serviço, ocorre o aumento da propensão do cliente / consumidor obter aquele produto ou serviço.

Segundo Porter (1989, p30), existem dois tipos básicos de vantagem competitiva, a saber: 1) liderança de custo e

2) diferenciação.

Cada uma dessas vantagens competitivas pressupõe a existência de uma estratégia competitiva, além de influenciarem a estrutura industrial na sua totalidade.

A liderança de custos ou vantagem de custos, além de ser um dos tipos básicos de vantagem competitiva, também influencia a diferenciação, pois o custo de um diferenciador 
deve estar próximo do custo da concorrência para ocorrer a compatibilização da necessidade do comprador com a capacidade para supri-la.

Para a obtenção de uma vantagem de custo, faz-se necessário que o custo acumulado de todas as atividades de valor esteja abaixo do alcançado pelos concorrentes. A sustentabilidade dessa vantagem lhe confere um valor estratégico. De acordo com Porter (1989, p.32), a cadeia de valor fornece o instrumento básico para a análise dos custos e como associar estes custos e ativos a atividades de valor.

A idéia de diferenciação está intimamente ligada a de valor quando percebida pelo comprador. Segundo Porter (1989, p.32), uma empresa diferencia-se da concorrência se puder ser singular em alguma coisa valiosa para os compradores. A Entidade é tida como detentora de um diferencial quando os consumidores enxergam valor no produto ou serviço que se apresenta como possuidor de singularidade, que muitas vezes é mostrada por meio de marcas.

O comportamento dos custos de uma empresa e a posição dos custos relativos provêm das atividades de valor por ela executadas. Depreende-se que uma análise de custos significativa examina os custos dentro destas atividades e da entidade como um todo, pois cada atividade de valor tem sua própria estrutura de custos e o comportamento destes pode ser afetado por elos e inter-relações com outras atividades dentro e fora da entidade.

Os esforços empreendidos para alcançar o objetivo de redução de custos envolvidos na cadeia logística levaram ao desenvolvimento de ferramentas que tornam possível o gerenciamento por três diferentes aspectos (cliente, custos e produto), que são respectivamente Customer Profitability Analysis (Análise da Lucratividade por Cliente), Total Cost of Ownership (Custeio Total de Aquisição) e Direct Product Profitability (Lucratividade Direta por Produto).

Neste estudo a ferramenta utilizada será a Lucratividade Direta por Produto. Para Freires (2000), "o sistema de custeamento por produto objetiva tornar o mais transparente possível a maneira como os custos (que vinham sendo considerados como fixos pelos sistemas contábeis tradicionais) varia com as decisões sobre produção, mix de produtos e diversificação da produção".

A técnica utilizada nesse sistema procura relacionar a receita obtida com determinado produto ou linha de produtos com os custos incorridos, à medida que se deslocam no fluxo logístico, afetando todos os elos da cadeia que se transformam em 
fornecedores. Da mesma forma, os distribuidores e varejistas também devem avaliar os custos na cadeia.

Christopher (1997, p.57) define o lucro direto do produto - DPP como" o termo atribuído à margem de lucro de um item que é calculada através do ajuste da margem bruta de cada produto". Os custos podem ser identificados, medidos e atribuídos diretamente ao produto individualmente (custos diretos do produto, tais como: mão-de-obra, embalagem, espaço, estoques e transporte etc.). Logo, a ferramenta permite que a análise da margem total do produto e, individualmente, de cada item que compõe a margem.

Esse tipo de análise, como será apresentado no estudo de caso, permite a entidade identificar quais direcionadores e atividades contribuem mais para a formação do custo individual do produto / serviço permitindo, aos gestores, tomadas de decisões específicas e eficazes para alcançar sua redução.

\section{Estudo de Caso: Redução de custos com o uso de arranjo produtivo local Leite \& Sol na cadeia de leite no Estado do Ceará}

Este estudo de caso apresenta a contextualização da cadeia produtiva do leite no Estado do Ceará para que se possa compreender a essencialidade dessa atividade produtiva para a economia carente do Estado, destacadamente para os pequenos e médios produtores rurais. Em seguida apresenta-se a alternativa de redução de custos na produção de leite a partir da estruturação do arranjo produtivo local denominado nesse estudo de APL Leite \& Sol. Finalizando, apresenta-se a redução de custos alcançada após o funcionamento do APL, considerando a análise através da ferramenta Lucratividade Direta por Produto.

\subsection{A Cadeia Produtiva do leite no Estado do Ceará e a estruturação em APL}

No Estado do Ceará, a atividade leiteira tem um importante papel na sobrevivência das propriedades agrícolas familiares, tanto no auto-consumo como na geração de renda, essa atividade permite a diversificação da propriedade e a integração agricultura-pecuária, 
especialmente no uso dos subprodutos agrícolas na alimentação das vacas e do esterco na adubação dos cultivos.

No que se refere a alimentação das vacas, destaca-se a torta de algodão, suprimento analisado neste estudo. O Ceará consome por ano em média 100.000 toneladas de torta de algodão por ano e mais 13.000 toneladas de óleo bruto, de forma que, toda a produção dos esmagadores de caroço a ser analisada tem mercado cativo no Ceará. Os esmagadores de caroço, que serão analisados, trabalham com a hipótese de que existe uma demanda completa para os seus produtos. Todavia, é importante que se destaque que esta demanda, segundo o sindicato de laticínios do Estado do Ceará é efetuada por 28.000 (vinte e oito mil) produtores rurais, dos quais apenas 4.000 (quatro mil) participam da cadeia produtiva que foi analisada. Desta forma, os esmagadores de algodão dispõem de estoques não só para satisfazer a demanda da rede, como também para suprir outros mercados consumidores.

A cultura do algodão é um complemento à atividade pecuária para alimentação do gado. Após o declínio da cultura do algodão no estado do Ceará, a partir de 1985 os produtores de leite passaram a buscar inúmeras alternativas de alimentação para o gado, mas sem obter êxito passaram a importar da Bahia e do Mato Grosso a torta de algodão.

No entanto, diante do elevado custo para aquisição da torta de algodão a produção de leite restringia-se às fábricas caseiras de produção de queijo e consumo local, dificultando uma produção em escala, também por conta da falta de logística de distribuição.

A partir de 1996, os elevados custos de transporte para a coleta do leite levaram a Cooperativa União a avaliar a possibilidade de adquirir o leite in natura, até então comprado em Pernambuco, dos 53 produtores rurais de Quixadá (CE), 13 de Iguatu (CE) e 17 de Juazeiro do Norte (CE), totalizando 83 produtores rurais de pequeno / médio porte.

O primeiro estágio de construção do arranjo produtivo surgiu quando os produtores e a cooperativa constaram, que individualmente seria inviável financeiramente o transporte do leite. A partir de então, passaram a compartilhar um transporte alugado de caminhão tanque que fazia a coleta em cada produtor de leite e entregava na usina de leite - Cooperativa União sediada em Fortaleza (CE). Esta cooperativa também refina e envasa óleos vegetais.

A partir da instalação da estrutura de coleta do leite in natura, surgiu um novo gargalo para a produção industrial em escala, que já era de conhecimento dos produtores rurais, o custo da alimentação do gado, ou seja, a torta de algodão. 
Surgiu então o segundo estágio de fortalecimento do APL. O primeiro aspecto a ser analisado neste estágio foi a redução do custo tributário. Como a base de cálculo do Imposto sobre a Circulação de Mercadorias e Serviços (ICMS) sobre a torta de algodão é maior que sobre o caroço de algodão devido o valor agregado, considerando-se como fornecedor o estado da Bahia, a melhor opção seria comprar o caroço. Logo, necessitava-se de um elo da cadeia produtiva instalada no Ceará que pudesse transformar o caroço em torta. Diante da cultura do algodão encontrar-se embrionariamente na região de Quixadá, a solução em APL seria a instalação de usinas esmagadoras para realizar este processo.

O grupo de produtores de Quixadá, Iguatu, Juazeiro do Norte e da Cooperativa União buscaram como parceiros para instalação das usinas esmagadoras duas empresas localizadas em Quixadá (CE), que possuíam instalações desativadas, e uma cooperativa na cidade de Cedro (CE).

Para a concretização do terceiro estágio, que foi a nova modelagem de cadeia de suprimento estruturada em APL, objeto desse estudo, os produtores de leite in natura e os esmagadores de caroço de algodão passaram a integrar a Cooperativa União. Essa incorporação foi essencial para a obtenção de financiamento junto a um banco de fomento visando à recuperação e atualização industrial das usinas esmagadoras.

A partir de então, a cadeia de suprimento do APL Leite \& Sol passou a funcionar conforme a Figura 1.

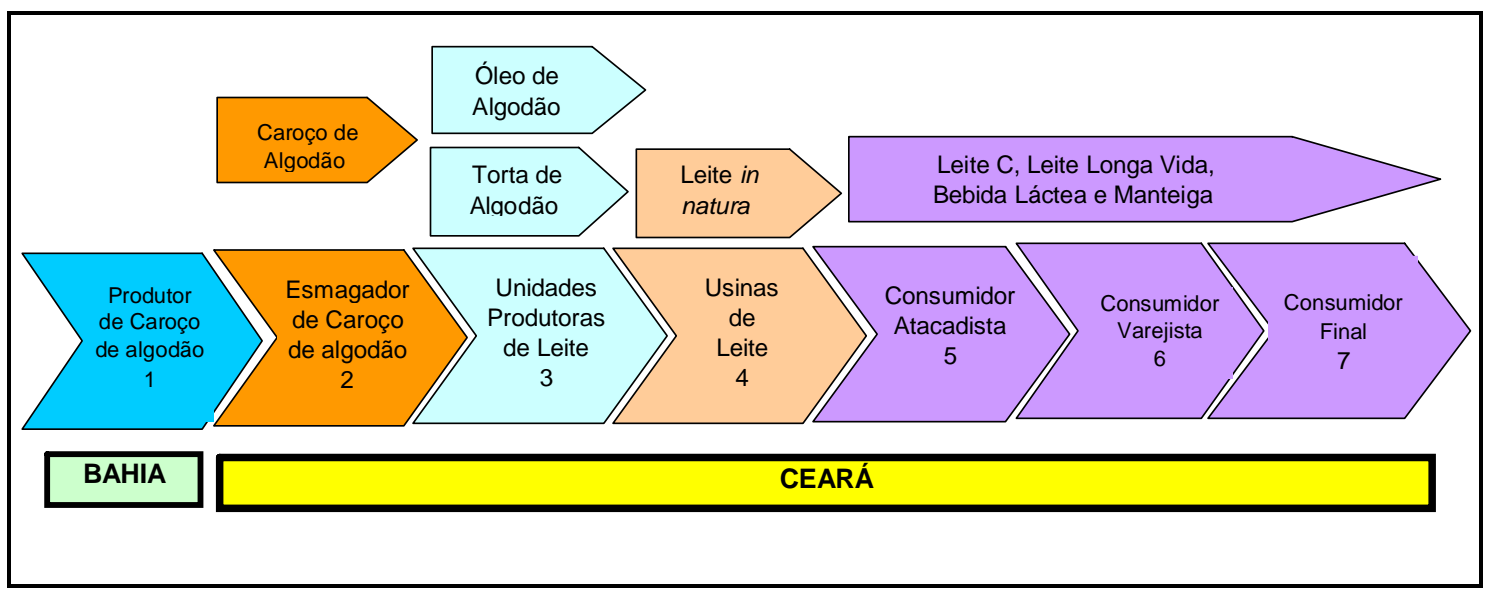

Figura 1: Cadeia de suprimento do APL Leite \& Sol.

Fonte: Elaborado pelos autores com base nas informações coletadas sobre a cadeia estudada. 
Com a nova modelagem, o elo 1 (produtor de caroço de algodão) ainda está situado no município de Luís Eduardo Magalhães (BA). Neste elo os produtores de algodão fazem seu beneficiamento separando a pluma, o caroço e o linter.

O caroço é comprado pelos produtores de leite e enviado para o elo 2, que são as usinas esmagadoras de caroço situadas em Quixadá (2) e em Cedro (1) no Estado do Ceará. As usinas esmagadoras produzem a partir do caroço dois produtos: óleo de algodão e torta de algodão. Ambos pertencem aos produtores de leite que pagam às usinas esmagadoras uma taxa pelo processo de industrialização. O óleo é vendido para a Cooperativa União e para outras empresas da iniciativa privada no Estado do Ceará favorecendo o fortalecimento da cadeia produtiva. E a torta de algodão é entregue aos produtores de leite (elo 3) e o seu excesso de produção não consumido pelos produtores de leite é destinado à comercialização ou é estocado para suprir os períodos de sazonalidade na produção do caroço e para manter estoque pulmão.

Logo, com um consumo de torta de algodão a um preço menor, as unidades produtoras de leite (elo 3) podem oferecer a matéria-prima, leite in natura, a um preço mais competitivo a usina de leite (elo 4) favorecendo os produtores de leite que passam a ter três importantes impactos no seu resultado: 1) Redução no pagamento de ICMS (impacto fiscal), 2) redução no custo de aquisição da torta de algodão (impacto operacional) e aumento na geração de receita com a venda de óleo de algodão bruto (impacto operacional).

Na seção a seguir apresentar-se-á, utilizando a ferramenta Lucratividade Direta por Produto, a redução dos custos no APL Leite \& Sol com a utilização de arranjos produtivos locais na gestão competitiva da logística de suprimentos.

\subsection{Análise da redução dos custos no APL Leite \& Sol}

A visão de cadeia produtiva ajuda os responsáveis pela tomada de decisão a tratar da questão de acesso a insumos e mercados na abordagem das atividades produtivas, considerando um menor custo. A cadeia do APL Leite \& Sol consumiu em 2005, 12.492 toneladas de caroço de algodão gerando um custo anual de $\mathrm{R} \$ 1.931 .066,25$. Os esmagadores 
de caroço de algodão colocaram a disposição da cadeia 9.707 toneladas de torta de algodão e 1.286 toneladas de óleo bruto, conforme evidencia a Figura 2.

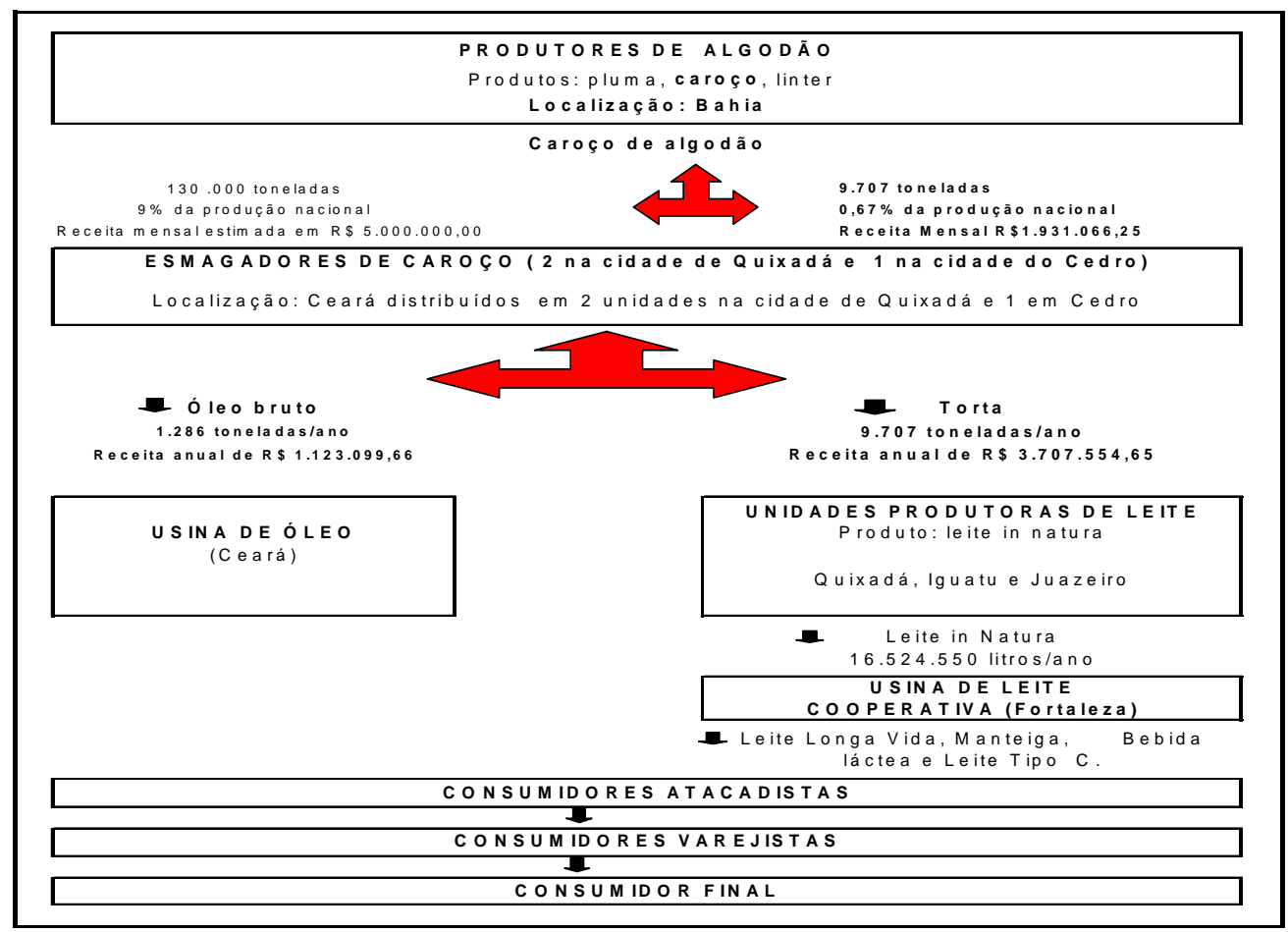

Figura 2 - Fluxos de Produtos na Cadeia do Algodão.

Fonte: Elaborado pelos autores com base nas informações coletadas sobre a cadeia estudada.

Para demonstrar a redução de custos na cadeia de suprimento do APL Leite \& Sol, foi necessário inicialmente identificar a quantidade de caroço de algodão adquirida pelos produtores de leite, bem como a produção de torta e óleo de algodão e a perda no processo. Os resultados encontram-se na Tabela 1, destacando-se a quantidade de torta produzida em 2005.

Tabela 1 - Produção de Torta e Óleo Bruto em 2005 por unidade esmagadora. 
$\underline{\text { www.producaoonline.ufsc.br }}$

ISSN 1676 - 1901 / Edição especial/dezembro de 2007 Artigo selecionado dos anais - XIV Congresso Brasileiro de Custos

\begin{tabular}{l|r|r|r|r|r}
\hline \multirow{4}{*}{ APL LEITE \& SOL } \\
\hline & $\begin{array}{r}\text { Comlat } \\
\text { (lguatu) }\end{array}$ & $\begin{array}{c}\text { Teclat } \\
\text { (Quixadá) }\end{array}$ & $\begin{array}{c}\text { Inovalat } \\
\text { (Juazeiro) }\end{array}$ & TOTAL \\
\cline { 2 - 6 } & \multicolumn{4}{|c}{ QUANTIDADE (EM TONELADAS) } \\
\hline Aquisição de Caroço de Algodão & 1.614 & 5.904 & 4.177 & 11.695 \\
Produção de Torta & 1.340 & $\mathbf{4 . 9 0 1}$ & $\mathbf{3 . 4 6 6}$ & 9.707 \\
Produção de Óleo de Algodão & 178 & 649 & 459 & 1.286 \\
Perdas no Processo & 97 & 354 & 251 & 702 \\
\hline
\end{tabular}

Fonte: Elaborado pelos autores com base nas informações coletadas sobre a cadeia estudada.

A Tabela 2 apresenta o detalhamento de custos de produção da torta de algodão obtidos por unidade de esmagamento de caroço.

Tabela 2 - Custo de Produção de Torta em 2005.

\begin{tabular}{|c|c|c|c|c|c|}
\hline \multirow[b]{2}{*}{ DESCRIÇÃO } & \multicolumn{3}{|c|}{ Unidades Esmagadoras de Caroço de Algodão } & \multirow[b]{2}{*}{$\begin{array}{c}\text { Total da } \\
\text { Produção } \\
\text { ( em Toneladas) }\end{array}$} & \multirow[b]{2}{*}{$\begin{array}{c}\text { Custo } \\
\text { Unitário } \\
\text { Médio (R\$) }\end{array}$} \\
\hline & $\begin{array}{l}\text { Raveltorta } \\
\text { (Cedro) } \\
\text { Produção } \\
\text { p/Comlat) }\end{array}$ & $\begin{array}{l}\text { ForteTorta } \\
\text { (Quixadá) } \\
\text { Produção p/ } \\
\text { Teclat }\end{array}$ & $\begin{array}{c}\text { Inditorta (Quixadá) } \\
\text { Produção } \\
\text { p/Inovalat }\end{array}$ & & \\
\hline \multirow[t]{2}{*}{ 1) Qde de produção de Torta de Algodão ( Tn ) } & 1.340 & 4.901 & 3.467 & 9.707 & - \\
\hline & $\begin{array}{l}\text { Raveltorta } \\
\text { (Cedro) } \\
\text { Produção } \\
\text { p/Comlat) } \\
\end{array}$ & $\begin{array}{l}\text { ForteTorta } \\
\text { (Quixadá) }\end{array}$ & Inditorta (Quixadá) & $\begin{array}{l}\text { Total da } \\
\text { Produção }\end{array}$ & $\begin{array}{c}\text { Custo } \\
\text { Unitário } \\
\text { Médio (R\$) }\end{array}$ \\
\hline 2) Custos de Produção & $(\mathrm{R} \$)$ & $(\mathrm{R} \$)$ & $(\mathrm{R} \$)$ & $(\mathbf{R} \$)$ & $(\mathrm{R} \$)$ \\
\hline 2.1.Caroço de Algodão & $262.378,60$ & $830.893,99$ & $837.793,66$ & $1.931 .066,25$ & 198,93 \\
\hline 2.2. Taxa de industrialização & $82.225,39$ & $66.824,70$ & $253.990,40$ & $403.040,49$ & 41,52 \\
\hline 2.3. Material de Embalagem & $20.098,53$ & $97.278,00$ & $51.946,60$ & $169.323,13$ & 17,44 \\
\hline 2.2. Fretes e Carretos & $128.261,13$ & $52.840,76$ & $323.022,89$ & $504.124,78$ & 51,93 \\
\hline Custos de Produção & $492.963,65$ & $1.047 .837,45$ & $1.466 .753,55$ & $3.007 .554,65$ & 309,83 \\
\hline Custo unitário ( ton ) & 367,91 & 213,81 & 423,12 & 309,83 & - \\
\hline
\end{tabular}

Fonte: Elaborado pelos autores com base nas informações coletadas sobre a cadeia estudada.

Observa-se que os custos unitários são diferentes entre nas unidades esmagadoras. Tais diferenças são, principalmente, decorrentes dos custos de fretes e carretos, devido às distâncias a serem percorridas para a entrega da produção, conforme observa-se pelo mapa apresentado na Figura 3. 
ISSN 1676 - 1901 / Edição especial/dezembro de 2007

Artigo selecionado dos anais - XIV Congresso Brasileiro de Custos

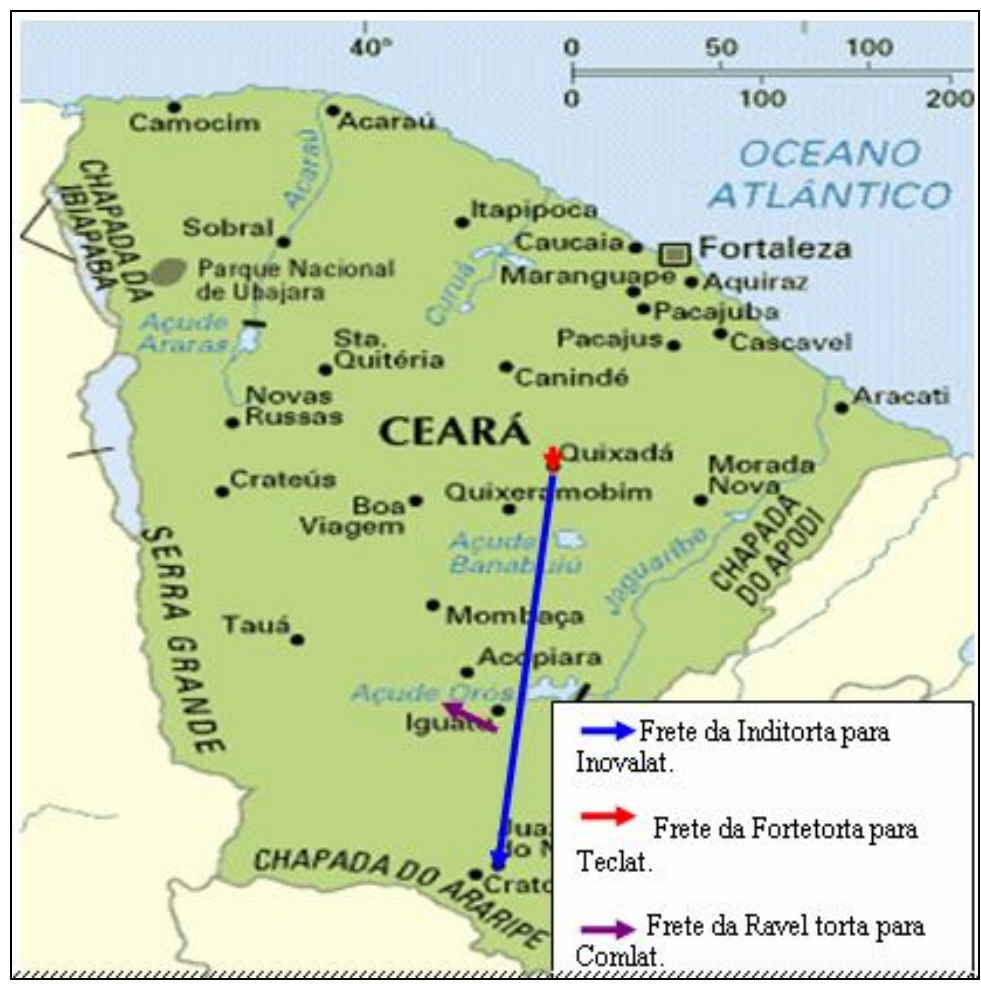

Figura 3 : Mapa de localização dos esmagadores para os produtores de leite.

Fonte: Adaptado de Amorim (1998)

Através da Tabela 2 e da Figura 3, nota-se que o maior custo concentra-se na produção da Inditorta (em Quixadá) enviada para a Inovalat (em Juazeiro do Norte).

O menor custo encontra-se na produção da Fortetorta (em Quixadá) para a Teclat (em Quixadá). Enquanto, a produção da Raveltorta (em Cedro) para a Comlat (em Iguatu) tem um custo afetado pela distância de municípios vizinhos e pelo baixo volume de produção, que pode exigir maior número de entregas com menor volume de carga.

O custo médio para a produção da torta de algodão na cadeia do APL Leite \& Sol é de $\mathrm{R} \$ 309,83$ por tonelada produzida.

Analisando-se a Tabela 3 pode-se observar a produção de leite e o consumo de torta de algodão no APL. Há uma relação que define que para cada 3 litros de leite produzidos o consumo é de $1 \mathrm{~kg}$ de torta de algodão, ou seja, aproximadamente, um terço da receita já está comprometido com este custo.

Além dos custos, existem as perdas de leite in natura, que no período de 2005 totalizou 675.032 litros. Tais perdas foram identificadas no processo de coleta do leite e no 
frete para as usinas. Vale salientar que um nível de perda de até $4 \%$ é considerado aceitável na atividade.

Tabela 3 - Produção de leite e consumo de torta de algodão no APL Leite \& Sol em 2005

\begin{tabular}{lcc}
\hline $\begin{array}{l}\text { Unidades Produtoras } \\
\text { de leite } \text { in natura }\end{array}$ & Produção de Leite in natura (litros) & \begin{tabular}{l} 
Consumo de $\begin{array}{c}\text { Torta dos Produtores } \\
\text { oriundas dos esmagadores Raveltorta, } \\
\text { Fortetorta e Inditorta (CE) (kg) }\end{array}$ \\
\hline Teclat (Quixadá - CE)
\end{tabular} \\
$\begin{array}{l}\text { Inovalat (Juazeiro }- \\
\text { CE) }\end{array}$ & 4.184 .250 & 1.394 .750 \\
Comlat (Iguatu-CE) & 8.925 .000 & 2.975 .000 \\
\hline Total & 3.415 .300 & 1.138 .433 \\
\hline
\end{tabular}

Obs. Perda na coleta e transporte de leite in natura em 2005 foi de 675.032 litros

Fonte: Elaborada pelos autores com base nos dados coletados nas empresas.

A Tabela 4 destaca a distribuição da produção de torta de algodão no arranjo produtivo, no exercício de 2005.

Tabela 4 - Distribuição de torta de algodão no APL Leite \& Sol em 2005

\begin{tabular}{lc}
\hline Distribuição da Torta de Algodão & Quantidade de torta (kg) \\
\hline Consumo entre os produtores de leite & $\mathbf{5 . 5 0 8 . 1 8 3}$ \\
Venda para outros produtores $(\mathrm{R} \$ 38,00 / \mathrm{kg})$ & 3.235 .497 \\
Estoque para o ano seguinte & 963.320 \\
\hline Total & $\mathbf{9 . 7 0 7 . 0 0 0}$ \\
\hline
\end{tabular}

Fonte: Elaborada pelos autores com base nos dados coletados nas empresas.

A produção de torta de algodão em 2005 atendeu o volume de consumo do APL, permitiu a realização de um estoque para o período seguinte e ainda gerou uma receita com a venda para outros produtores que não pertenciam ao arranjo com uma margem de lucro de $12 \%$. 
Para demonstrar a gestão estratégica de custos na cadeia e a análise individual realizada pela Lucratividade Direta por Produto, segue na Tabela 5 uma análise comparativa entre a situação atual do arranjo e a aquisição da torta de algodão na Bahia.

Tabela 5 - Demonstrativo do resultado gerado no uso do Arranjo Produtivo Local Leite \& Sol.

\begin{tabular}{|c|c|c|c|c|c|}
\hline \multirow{2}{*}{\multicolumn{2}{|c|}{ AQUISIÇÃO DA TORTA DE ALGODÃO COM APL }} & \multirow{2}{*}{\multicolumn{2}{|c|}{ AQUISIÇÃO DA TORTA DE ALGODÃO SEM O APL }} & \multicolumn{2}{|c|}{ ECONOMIA } \\
\hline & & & & \multirow{2}{*}{$\begin{array}{c}\text { VALOR }(\mathbf{R} \$) \\
- \\
\end{array}$} & \multirow[t]{2}{*}{$\%$} \\
\hline Qtde Consumida ( tn ) & 5.508 & Qtde Consumida (tn ) & 5.508 & & \\
\hline Custo unitário médio $\mathrm{R} \$(\mathrm{tn})$ & 309,83 & Custo unitário R\$ ( tn ) & 427,00 & 117,17 & $27,44 \%$ \\
\hline Custo de Produção (R\$) & $1.706 .545,48$ & Custo de Aquisição (R\$) & $2.351 .916,00$ & $645.370,52$ & \\
\hline Qtde Vendida ( tn ) & 3.236 & Qtde Adquirida (tn ) & 3.236 & & \\
\hline Custo unitário médio $\mathrm{R} \$(\mathrm{tn})$ & 309,83 & Custo unitário R\$ ( tn ) & 380,00 & 70,17 & \\
\hline Custo de Produção (R\$) & $1.002 .610,96$ & Custo de Aquisição (R\$) & $1.229 .680,00$ & $227.069,04$ & \\
\hline Qtde Estocada ( tn ) & 963 & Qtde Adquirida (tn ) & 963 & & \\
\hline Custo unitário médio $\mathrm{R} \$(\mathrm{tn})$ & 309,83 & Custo unitário R\$ ( tn ) & 427,00 & 117,17 & $27,44 \%$ \\
\hline Custo de Produção (R\$) & $298.366,61$ & Custo de Aquisição (R\$) & $411.201,00$ & $112.834,39$ & \\
\hline \multirow[t]{2}{*}{ Total de Torta Produzida } & 9.707 & & & & \\
\hline & & & \multicolumn{2}{|c|}{ Resultado do APL } & \\
\hline \multirow{2}{*}{\multicolumn{2}{|c|}{ PRODUÇÃO DE ÓLEO BRUTO DE ALGODÃO }} & & Consumo de torta & $645.370,52$ & \\
\hline & & & Venda de torta & $227.069,04$ & \\
\hline Qtde Produzida (ton ) & 1.286 & & Estoque de torta & $112.834,39$ & \\
\hline Preço de venda ( ton ) & 873,00 & & Produção de óleo de algodão & $1.123 .099,66$ & \\
\hline Receita de vendas (R\$) & $\overline{1.123 .099,66}$ & & Total & $2.108 .373,61$ & \\
\hline
\end{tabular}

Fonte: Elaborado pelos autores com base nos dados coletados.

Na Tabela 5, observa-se que o custo de produção da torta de algodão em 2005, utilizando-se o APL, foi de $\mathrm{R} \$ 309,83$ por tonelada, enquanto no modelo anterior comprariam por $\mathrm{R} \$ 427,00 /$ tonelada aos esmagadores da Bahia. Esse novo processo de suprimento de torta de algodão gerou um resultado bruto positivo para os produtores de leite do APL no valor de $\mathrm{R} \$ 645.370,52$.

Considerando-se que os produtores precisam manter estoques mínimos ou de sazonalidade, estes alcançaram com a implementação do APL um resultado bruto favorável de $\mathrm{R} \$ 112.834,39$.

Além destes resultados inerentes a atividade de criação de gado leiteiro, os produtores de leite auferiram resultados com a venda do excedente de torta para outros produtores e também com a venda de óleo de algodão resultante do esmagamento do caroço. 
Com a venda da torta ao preço de $\mathrm{R} \$ 380,00$ / tonelada os produtores obtiveram um resultado bruto de $\mathrm{R} \$ 227.069,04$. E com a venda do óleo ao preço de $\mathrm{R} \$ 873,00$ / tonelada obteve um resultado bruto positivo de $\mathrm{R} \$ 1.123 .099,66$.

Totalizando esses resultados conclui-se que os produtores de leite com o uso do arranjo produtivo local conseguiram obter um resultado bruto favorável em 2005 de $\mathrm{R} \$ 2.108 .373,61$, o que corresponde em média a um resultado médio bruto mensal de $\mathrm{R} \$ 175.697,80$.

É importante ressaltar que há uma inconsistência no cálculo real dos custos do APL que está contemplada no estudo de caso. Trata-se do não reconhecimento de custos na produção do óleo em relação à aquisição do caroço de algodão. As entidades consideram o total desse custo na produção da torta, quando o mesmo deveria ser tratado de forma a contemplar a sua participação na produção da torta e do óleo.

\section{Conclusões}

Atualmente, são cada vez mais notáveis os esforços empresariais em direcionar a estratégia corporativa para geração de diferencial competitivo. Esses esforços tendem a fazer com que a empresas foquem seus recursos nas atividades que são indispensáveis à manutenção de seu negócio e, ao mesmo tempo, procurem otimizar seu desempenho global através da utilização de parceiros que tenham excelência nas demais atividades necessárias a sua atuação junto ao mercado. Neste panorama, fica clara a importância da desintegração de processos da empresa e a conseqüente substituição do modelo de empresa autônoma e voltada para produção em massa para o modelo de produção flexível através de redes de empresas interdependentes.

A estratégia de estabelecer vínculos entre pequenas empresas para buscar vantagens competitivas no mercado, está oferecendo para pequenos negócios a oportunidade de se tornarem competitivos e, com isso, se manter no mercado. Esses vínculos entre as empresas, formando aglomerações, fortalecem as chances de sobrevivência e de crescimento das mesmas e constitui-se uma importante fonte geradora de vantagens competitivas. É através dessas ligações que se forma um processo de aprendizagem coletiva, cooperação e dinâmica 
de inovação desses conjuntos de empresas, que se tornou fundamental para enfrentar os desafios impostos pelo mercado globalizado.

Através da análise das potencialidades, vocações e oportunidades do território onde está inserido o arranjo produtivo local é que são construídas as vantagens competitivas sustentáveis de cada APL. Os APLs, assim como os clusters, devem ser embrionários no seu território, pois nem o custo nem o risco de implementação compensam a criação dos mesmos.

Para o desenvolvimento e manutenção de um arranjo produtivo na atual conjuntura econômica, social e empresarial faz-se necessário compreender todos os fatores que levam à implementação da vantagem competitiva, para modelar sua estrutura na cadeia de suprimento de modo a gerar o melhor resultado para o arranjo, buscando-se também o melhor resultado individual para as empresas.

Diante das análises realizadas no ano de 2005, o arranjo produtivo apresentado nesta pesquisa demonstrou ser uma estratégia para redução de custos para que as 83 microempresas participantes tenham tornado mais produtivas, competitivas e lucrativas, sob o aspecto coletivo. Como foi observado, os custos unitários apresentaram-se diferentes entre as unidades esmagadoras no período analisado. Tais diferenças foram, principalmente, decorrentes dos custos de transporte, devido às diferentes distâncias a serem percorridas para a entrega da produção da torta de algodão, isto é, o resultado coletivo foi influenciado significantemente pelas distâncias percorridas.

Conclui-se que o APL analisado apresentou-se técnica e economicamente viável, apresentando um resultado positivo no período analisado. Destaca-se, que graças e esse arranjo, foi possível a venda de um novo produto pelos produtores de leite que surgiu graças ao APL (óleo bruto de algodão), como também a existência de economia no custo de aquisição da torta de algodão, que além de ter atendido o volume de consumo do APL, permitiu a realização de um estoque para o período seguinte e ainda gerou uma receita com a venda para outros produtores que não pertenciam ao arranjo e que se beneficiam na cadeia com a redução de custo.

Portanto, a problemática do estudo foi solucionada e os objetivos foram alcançados, pois foi constatado, no período analisado, uma redução dos custos com o uso de arranjos produtivos locais na gestão competitiva da logística de suprimentos no APL Leite \& Sol. 
É importante ressaltar que eficiência coletiva não significa necessariamente que todas as empresas analisadas no estudo estejam crescendo na mesma proporção, pois o fator competitividade continua inerente, mesmo nesta estrutura produtiva. $\mathrm{O}$ que passa a acontecer é a existência de um mercado e relações mais transparentes que podem incitar tanto a competição quanto a cooperação, resultando em crescimento para algumas empresas enquanto outras podem reduzir os seus resultados, mantendo coletivamente um resultado favorável, contribuindo para o crescimento local.

Independentemente do conceito que seja dado a aglomeração produtiva do setor estudado é importante que esteja claro que o sucesso da aglomeração estará pautado na iniciativa privada e no trabalho conjunto dos empresários do setor. O amadurecimento e evolução da aglomeração como APL depende de como as ações sejam desenvolvidas, de forma cooperativa e compartilhadas, e as iniciativas devem ser do setor privado. Em coletividade é possível fazer reivindicações, com probabilidade maior de serem atendidas.

Ainda com relação ao pensamento coletivo, não pode ser esquecido que a globalização dos mercados abriu estes para outros possíveis consumidores, mas também para novos concorrentes. E a maior e mais forte concorrência não é aquela que se consegue enxergar todos os dias, mas é justamente aquela que é desconhecida, e cujo potencial não se pode medir. Esta concorrência só é possível de ser vencida quando forças são unidas, em torno de um interesse comum. E os maiores interessados em fazer o setor prosperar, não poderão ser outros senão os proprietários das empresas que compõem o setor.

Vale ressaltar, que o sucesso do setor como uma aglomeração produtiva efetiva somente ocorrerá se as ações de cooperação de fato ocorrerem. Para tanto, cabe aos agentes locais, mas principalmente aos empresários, organizarem-se no sentido de que a aglomeração venha a contemplar também outras características pertinentes aos APLs, e em seguida aos SPLs, atingindo a plenitude do conceito do sistema sociotécnico, que contempla aspectos técnicos e sociais objetivando atingir o estado de melhor organização do sistema através de uma visão sinérgica. 


\section{REFERENCIAS}

AMARAL FILHO, Jair do. É negócio ser pequeno, mas em grupo. Texto apresentado no Desenvolvimento em Debate, painéis do Desenvolvimento Brasileiro II. 2000.

AMORIM, M. A. Clusters como estratégia de desenvolvimento industrial no Ceará. $1^{\mathrm{a}}$ ed. Fortaleza: Banco do Nordeste. 1998.

BASTOS, M. M. de M. Notas de aula da disciplina Fundamentos da Logística do mestrado de Logística e Pesquisa Operacional (UFC), (2007).

CHRISTOPHER, Martin. Logística e gerenciamento da cadeia de suprimentos: Estratégia para redução de custos e melhoria dos serviços. São Paulo: Pioneira, 1997.

FREIRES, F. G. M.. Proposta de um modelo de gestão de custos da cadeia de suprimentos. 2000.135 p. Dissertação. (Mestrado em Engenharia de Produção) Universidade Federal de Santa Catarina.

LEMOS, Cristina. R. Micro, Pequenas e Médias Empresas no Brasil: novos requerimentos de políticas para a promoção de sistemas produtivos locais. Tese (Doutorado em Engenharia de Produção). UFRJ, Rio de Janeiro, 2003.

MACHADO, S. A. Dinâmica dos arranjos produtivos locais: um estudo de caso em Santa Gertrudes, a nova capital da cerâmica Brasileira. Tese (Doutorado em Engenharia de Produção). EP-USP, São Paulo, 2003.

MARSHALL, A. Industry and Trade: A Study of industrial technique and businnes organization; and of their influences on the condition of various classes and nations. Online book. 1920. Disponível em < http://www.econlib.org/library/marshall/marPtoc.html> Acesso em: novembro de 2006.

PAGANI, Regina N.; et al. Uma análise do controle de qualidade utilizado pelas empresas do setor de Móveis de Metal e Sistemas de Armazenagem e Logística de Ponta Grossa, PR. XXVI ENEGEP. Anais... Fortaleza. Brasil. Outubro de 2006b.

PORTER, M. Clusters e competitividade. Tradução por HSM Management. Revista HSM Management, p.100 - 110, julho/agosto, 1989.

REDESIST. Glossário de Arranjos Produtivos e Sistemas Inovativos e Produtivos Locais. 5a. revisão. Junho, 2005.

SCHMITZ, H. Eficiência Coletiva: caminho de crescimento para a indústria de pequeno porte. Ensaios FEE. Porto Alegre, v.18, n.2, p.164-200, 1997. 
SUZIGAN, W. Aglomerações industriais: avaliação e sugestões de políticas. Disponível em: <http://www.desenvolvimento.gov.br/arquivo/sti/publicacoes 01.pdf>. 2000. Acesso: janeiro de 2007. 